\section{Drug and solvent misuse in national school children in mid-west Ireland}

Dear Editor - Studies in Ireland, ${ }^{1-3}$ the $U K_{,}{ }^{4}$ the rest of the $\mathrm{EU},{ }^{5}$ and further afield, ${ }^{6}$ indicate levels of drug misuse among children and adolescents that are a cause of serious concern. In 1997, the Mid-Western Health Board undertook a baseline study to examine health status and behaviours of adolescents in the region, ${ }^{7}$ and completed a follow-up study in $2002 .{ }^{8}$ In the latter study it was noted that some young people reported experimentation with drugs, alcohol and tobacco, while a minority of children aged 13 years and younger reported regular use. This suggested the need for future exploration of these issues with younger children. The present study was conducted to examine the current extent of tobacco, alcohol and drug use among national (primary) school children in the Mid-West region. This short paper focuses on the results concerning drug and solvent misuse and the availability of information about drug and solvent misuse and its effects. A brief overview of alcohol use is also reported.

\section{Methods}

Ethical approval for this study was given by the Ethics Research Committee of the Regional General Hospital, HSE-Mid Western Area. The survey instrument used in this study with children incorporated elements from previously published questionnaires.

The questions concerning drug and glue/solvent misuse were drawn from the Health Behaviour in School-aged Children (HBSC) survey. ${ }^{3}$

The study population was drawn from fifth and sixth class pupils (years seven and eight) attending national schools in the Mid-West region of Ireland. Fifty schools were randomly selected from a geographically stratified sample (Limerick City, Limerick County, County Clare and North Tipperary), with a quarter of the schools selected from each area.

A total of 43 schools finally participated in the survey. Active parental consent was a condition of inclusion in this study. The response rate, calculated inclusive of children in the non-participating schools, was $76.2 \%$.

The confidential questionnaire was completed by 1,255 participants. The questionnaire returned from one pupil was excluded from the analysis based on a positive response to the question on having used the fictitious drug Mexaval. Of the remaining 1,254 children, 573 were males and 681 were females. Participants ranged in age from 10-14 years of age (although only two were aged 14), with $47 \%$ (588) coming from fifth class and the remainder from sixth class. The mean age of the participants was 11.5 years $(S D=0.73$ ).

\section{Results}

Of the respondents overall $1 \%(n=12)$ reported that they had ever used cannabis. Eight of these respondents were male and four female (chi square analysis did not find this gender difference to be statistically significant; $\chi^{2}=1.379$, $\mathrm{df}=1, \mathrm{p}=0.2403$ ). Only two respondents reported having used cannabis more than 'once or twice'.

A total of $1.3 \%(n=16)$ of respondents reported having ever taken 'any other drug'. Although 13 out of 16 of these had only ever done so 'once or twice', 13 of the children who reported lifetime usage were male and just three were female. This gender difference was identified as statistically significant $\left(\chi^{2}=6.869, d f=1, p=0.0088\right)$.

Although $95.8 \%(n=1,195)$ of respondents reported never having used glue/solvents in their lives, $4.2 \%(n=53)$ did admit to having used such substances at least 'once or twice'. Once again, although 44 out of the 53 replied that they had only ever done this 'once or twice', the majority of those admitting lifetime usage of glue/solvents were male (33). Chi-square analysis revealed the higher frequency of males to have ever used glue/ solvents to be statistically significant $\left(\chi^{2}=5.446, d f=1, p=0.0196\right)$.

A total of $83.8 \%(n=1,048)$ of respondents stated that they had heard of cannabis, whilst $16.2 \%(n=203)$ stated that they had not. Pupils were asked whether they thought their school provided them with enough information about illegal drugs and their effects and consequences. Overall, 25\% ( $n=316$ ) of pupils thought that they were given sufficient information, $45 \%$ ( $n=564$ ) felt that they needed more information (24\% a little more, $21 \%$ a lot more) and nearly $20 \%$ $(n=249)$ stated that they were given no information at all.

A total of $72.8 \%(n=903)$ of pupils overall reported that they had ever tasted alcohol, even if it was only a sip. However only $10.8 \%(n=134)$ of the respondents overall reported having consumed a whole alcoholic drink. More males $(64.9 \%, n=87)$ than females $(35.1 \%, n=47)$ reported having ever consumed a whole alcoholic drink. Less than $1 \%$ of respondents reported weekly use of alcohol.

When asked whether they had ever had so much alcohol that they were really drunk, $94 \%$ of the children stated that they had never been drunk, with $6 \%$ overall admitting to having been drunk. Of these who reported having ever been drunk, $60 \%(n=45)$ were males and $40 \%(n=30)$ were females.

\section{Conclusions}

This study provided a baseline assessment of the level of drug and solvent misuse by national school children in the Mid-Western region of Ireland. Although the results are encouraging in relation to cannabis and may dispel anecdotal concerns, there is clearly no room for complacency. The level of experimentation with glue/solvents, particularly among males, is an issue given its potential lethality.

It is clear that respondents perceive that they are not receiving the level of information about drugs that they would like. The results from this survey should be noted by school-based health educators, particularly in relation to the mandatory inclusion of social, personal and health education (SPHE) in national schools.

One limitation of this survey should be noted. This survey focussed only on those children attending national school on the survey date and was conducted on the basis of informed 
parental consent. It is probable that children from more chaotic backgrounds where drug misuse may be an issue were under-represented in this study.

Frank Houghton, Lecturer, Department of Humanities, Limerick Institute of Technology, Limerick, Ireland,

Hilary Cowley, Research Officer, Department of Public Health, Limerick, HSE West, Ireland,

Fiona Meehan, Research Assistant, Psychology Department, Mary Immaculate College, Limerick, Ireland, Kevin Kelleher, Assistant National Director, Health Protection, HSE, Ireland

\section{References}

1. Flanagan E, Bedford D, O'Farrell A, Howell F. Smoking, Alcohol and Drug Use among Young People. Ireland: Department of Public Health, North Eastern Health Board, 2003.

2. Friel S, NicGabhainn S, Kelleher C. National Health and Lifestyle Surveys: Survey of Lifestyle Attitudes and Nutrition (SLAN) and the Irish Health Behaviour in School-aged Children Survey (HBSC). Galway: Centre for Health promotion Studies, NUI Galway, 1999 .

3. Kelleher C, NicGabhainn S, Friel S. National Health and Lifestyle Surveys: Survey of Lifestyle Attitudes and Nutrition (SLAN) and the Irish Health Behaviour in School-aged Children Survey (HBSC). Galway: Centre for Health promotion Studies, NUI Galway, 2003.

4. Fuller $E$ (ed). Smoking, drinking and drug use among young people in England in 2004. London: Health and Social Care Information Centre, NICE, 2005.

5. Hibell B, Andersson B, Bjarnason T et al. The ESPAD Report 2003. Alcohol and Other Drug Use Among Students in 35 European Countries. Stockholm: The Swedish Council for Information on Alcohol and Other Drugs (CAN) and the Pompidou Group at the Council of Europe, 2004

6. Norris TF, Eyeson-Annan ML. Recent substance use and high levels of psychological distress among secondary school students in New South Wales. NSW Pub Health Bull 2007 Jul-Aug; $18(7-8)$ : 125-9.

7. Gleeson M, Kelleher K, Houghton F, Feeney A, Dempsey $H$. Teenage smoking, drug + alcohol use in the Midwest. Limerick: Mid-Western Health Board, 1998.

8. Kelleher $\mathrm{K}$, Cowley $\mathrm{H}$, Houghton $\mathrm{F}$. Teenage smoking, drug and alcohol use in the Mid-Western Health Board Region 2002. Limerick: Mid-Western Health Board, 2004.

\section{Multiple pathways on the route to recovery}

Dear Editor - In Facilitating journey to recovery - Ir J Psych Med 2008; 25(3) Khan and Murray ${ }^{1}$ recently outlined the requirement for a multidisciplinary assessment by a rehabilitation and recovery team and the use of a comprehensive assessment tool to help guide mental health service users toward recovery. The authors restate the Expert Group on Mental Health Policy ${ }^{2} A$ Vision for Change recommendation that a recovery orientation inform every aspect of service delivery.

Unlike the authors, we do not believe that a specialist comprehensive initial assessment is always 'crucial in order to identify needs and the rehabilitation goals for [or even of] the service user'. The US SAMHSA (Substance Abuse and Mental Health Services Administration) 2006 Consensus Statement on Mental Health Recovery ${ }^{3}$ sets out 10 fundamental components of recovery, including that journeys be individualised and person-centred. Recognition is given to the fact that 'there are multiple pathways to recovery based on an individual's unique strengths and resiliencies as well as his or her needs, preferences, experiences, and cultural background'. Many people who come into contact with mental health services are capable of assessing their own needs and determining their own path to recovery with minimal or even no professional support.

It is interesting to note that the CASIG (Client Assessment of Strengths, Interests and Goals) validation studies ${ }^{4,5}$ were based on data collected by 18 peer-interviewers with serious and persistent mental illness. The research team reported $90 \%$ accuracy for task performance based on examination of CASIG documentation and audio records of the interviews. ${ }^{5}$ On the other hand, there are service users with severely functionally disabling mental illness or more complex needs who require significant specialist rehabilitation assistance.

We are currently testing the utility of the CASIG as part a larger rehabilitation and recovery process pilot within our residential rehabilitation service. This experience allows us to usefully add to the author comments on its use in this context. In this population administration often exceeds the suggested range of 60-90 minutes and requires significant staff skill to assist both in the formulation of realistic and attainable goals and in incremental plans to achieve them. Also, while the framework is recovery based, it is possible (and sometime easy) to deviate from recovery principles within the structure.

Significant effort has to be given to staff training in recovery principles and practice and to the maintenance of a recovery ethos. While the CASIG is wide ranging it is by no means all encompassing. We use a small number of core additional assessments to inform care planning. These include a Rehabilitation Readiness Assessment (to determine whether an individual desires and is sufficiently skilled to engage in a comprehensive formal rehabilitative process at this time), a risk assessment, and an independent physical health assessment. Not infrequently more specific testing or assessments are required to delineate strengths and barriers to recovery.

While assessment tools such as the CASIG may aid our efforts, implementing $A$ Vision for Change recommendations in a truly meaningful way will involve sustained organisational commitment to the core principles of recovery.

Majella Cahill \& Elaine Collins Burton Hall Rehabilitation and Training Centre, Sandyford Industrial Estate, Sandyford, Dublin 18, Ireland

\section{References}

1. Khan $H$, Murray E. Facilitating journey to recovery. Ir J Psych Med 2008; 25(3):77-79.

2. A Vision for Change: Report of the Expert Group on Mental Health Policy. 2006. http://www.dohc.ie/publications/pdt/vision_for_change.pdf?direct $=1$

3. SAMHSA National Consensus Statement on Mental Health Recovery. 2006. http:// mentalhealth.samhsa.gov/publications/allpubs/sma05-4129/.

4. Wallace CJ, Lecomte T, Wilde J, Liberman RP. CASIG: a consumer-centered assessment for planning individualized treatment and evaluating program outcomes. Schiz Res 2001; 50: 105-119.

5 . Lecomte T, Wilde JB, Wallace CJ. Mental health consumers as peer interviewers. Psychiat Serv 1999; 50: 693-695.

\section{The economic cost of schizophrenia in Ireland}

Dear Editor - This is in reference to the interesting article The economic cost of schizophrenia in Ireland: a cost of illness study'. Behan et al; Ir J Psychological Medicine 2008; 25(3). ${ }^{1}$ This study provides a very useful evidence for the 